\title{
Obtainment of the Envelope Graph of Bending Moments of the Solid Model of Slab Ballastless Track
}

\author{
Jun Luo ${ }^{1, a}$, Zhiping Zeng ${ }^{2, b^{*}}$, Xiaobai Meng ${ }^{3, c}$ and Shanyi Song ${ }^{4, d}$ \\ 1, 2, 3, ${ }^{4}$ School of Civil Engineering Central South University Changsha, China

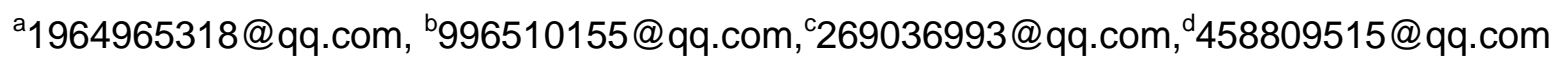

Keywords: Ballastless track; Solid model; Finite element internal force method; Envelope graph of bending moments

\begin{abstract}
When designing and calculating through ANSYS software, there exist many solid models that are unable to be simplified as the beam or shell. In order to obtain the distribution of internal force of these structures to guide the optimization design, the paper puts forward a method to obtain the envelope graph of bending moments of solid models through the secondary development of ANSYS software on the basis of the principles of the finite element internal force method. The method is applied to CRTS I ballastless track structure on subgrade to analyze the longitudinal and transverse envelope graph of the bending moments under the action of the design wheel load or the common wheel load with temperature gradient. The method is useful for the optimization design of the ballastless track structure and can be applied to obtain the envelope graph of bending moments, shear or axial force of structures in other fields, which can't be simplified as the beam or shell element.
\end{abstract}

\section{Introduction}

When analyzing the stress of various engineering structures through the application of the finite element method, we can make judgments based on the calculated stress state, which is accurate and reasonable theoretically. But in many cases, in addition to comprehending the stress state of structures, we need to determine reliability and make structural designs according to the axial forces, shear forces and bending moments of certain dominative cross-sections of structures [1]. Therefore, it's of great significance to obtain the structure internal force diagram.

Ballastless track is usually emulated and simulated by the beam-solid model and beam-shell model. It's convenient to develop the beam-shell model and the boundary conditions are relatively simple, but the model often can't reflect the actual stress of ballastless track. When calculating the warping stress under temperature gradient, or considering the influence of cracks, concrete creep and other factors, the solid model has to be used.

ANSYS is the universal finite element software, which has favorable openness and provides various ways of the secondary development. The users can extend the function and inherit the system in the standard ANSYS version according to their own needs [2]. Ref. [3] obtains the average effect of the internal force of each section by the method of obtaining the internal force through the secondary development of ANSYS. When the difference of the internal force in the cross-section is not distinct, the method is feasible; on the contrary, the structure internal force diagram is needed to get the most unfavorable position to guide the structure design.

The paper uses the finite element software ANSYS as a platform, it obtains the longitudinal and transverse envelope graph of bending moments of the track board in different load conditions based on the principle of finite element internal force method [4-6] through the secondary development of the APDL language, which makes certain guiding significance for the design of ballastless track structure.

\section{The Obtainment of The Envelope Graph of Bending Moments of Ballastless Track Board}

Calculation Model. Taking CRTS I slab ballastless track as the research object [7-10], the refined model in Fig. 1 is established through ANSYS and the convex block station is neglected in order to 
control the mesh easily, meanwhile, the size effect of the fastener is considered, namely, the nodes on the rail are connected with the corresponding nodes in the size range of fasteners on the track board so as to eliminate stress concentration. The rail is simulated by beam 188 element, the track board, CA mortar and base board are simulated by solid185 element and the fasteners and subgrade are both simulated by combination 14 element.

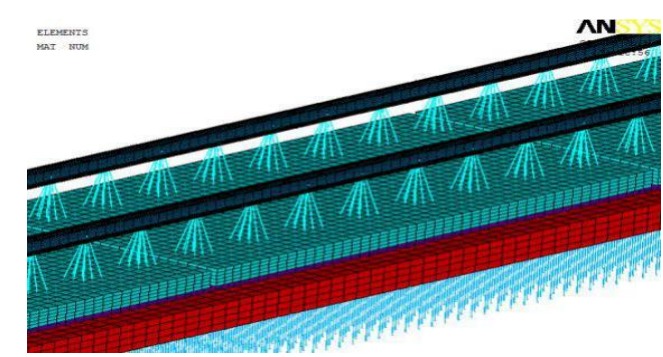

Figure 1. The finite element model of CRTS I slab ballastless track

Load Conditions. The design wheel load or common wheel load with temperature gradient are the main forces for the reinforcement design for the element slab ballastless track on subgrade. According to this, this paper uses two kinds of load conditions (Table 1), the train loads are loaded as a single wheelset, which are loaded on the rail successively from the end of the track board, the midpoint of adjacent fasteners to the top of the fasteners.

Table 1 The design loads of CRTS I slab ballastless track on subgrade

\begin{tabular}{|c|c|c|}
\hline Conditions & Condition 1 & Condition 2 \\
\hline Items & design wheel load & common wheel load with temperature gradient \\
\hline Values & $300 \mathrm{kN}$ & $-5^{\circ} \mathrm{C} \sim+10^{\circ} \mathrm{C}$ \\
\hline
\end{tabular}

The Envelope Graph of Bending Moments of Ballastless Track Board in Condition 1. Fig. 2 illustrates that the longitudinal positive bending moments along the length of the board change with alternating peaks and troughs in condition 1, which reach the peak on the cross-sections of the track board below the fasteners and drop about 60 percent to the trough between the fasteners. When the train loads are acted on the rail above the middle fastener, the bending moments reach its maximum value of $22.454 \mathrm{kN} \cdot \mathrm{m} / \mathrm{m}$ and the longitudinal positive bending moments along the width of the board are relatively small on the end and middle of the board with the value of $10.907 \mathrm{kN} \cdot \mathrm{m} / \mathrm{m}$ and $8.565 \mathrm{kN} \cdot \mathrm{m} / \mathrm{m}$. As for the longitudinal negative bending moments, they vary smoothly along the width and tend to be stable along the length after increasing from the end of the board to the second fastener, which reach its maximum value of $3.743 \mathrm{kN} \cdot \mathrm{m} / \mathrm{m}$ on the cross-sections of the board below the fourth and the fifth fastener when the rail above the end fastener is loaded.

Fig. 3 illustrates that the transverse positive bending moments along the length of the board change with alternating peaks and troughs, which reach the peak on the cross-sections of the track board below the fasteners and drop about 40 percent to the trough between the fasteners. When the train loads are acted on the rail above the end fastener, the bending moments reach its maximum value of $20.238 \mathrm{kN} \cdot \mathrm{m} / \mathrm{m}$ on the corresponding cross-section. Along the width, there exist sections of $0.28 \mathrm{~B}$ ( $\mathrm{B}$ is the width of the track board)with the value of approximate zero of the bending moments near the center of the board. As for the transverse negative bending moments, when the train loads are acted on the rail at the end of the board, the bending moments reach its maximum value of $7.366 \mathrm{kN} \cdot \mathrm{m} / \mathrm{m}$ and there exist sections of $0.32 \mathrm{~B}$ with the value of approximate zero of the bending moments near the end of the board. 


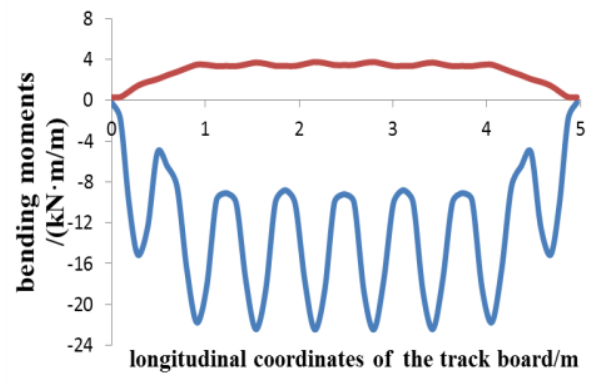

(a) distribution along the length of the board

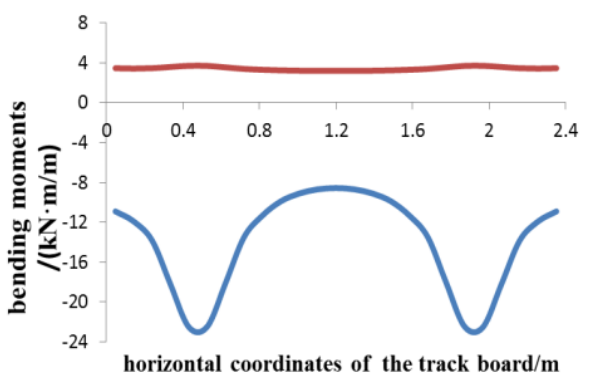

(b) distribution along the width of the board

Figure 2. The longitudinal envelope graph of bending moments in condition 1

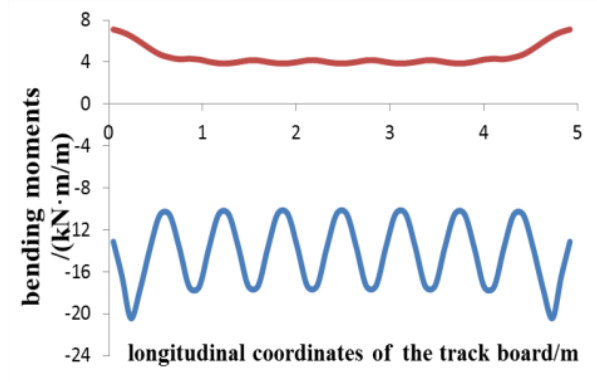

(a) distribution along the length of the board

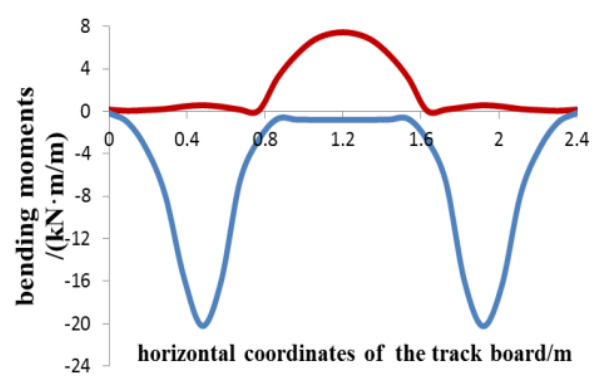

(b) distribution along the width of the board

Figure 3. The transverse envelope graph of bending moments in condition 1

The Envelope Graph of Bending Moments of Ballastless Track Board in Condition 2. Fig. 4 illustrates that the distribution of the longitudinal positive bending moments along the length of the board is similar to that in condition 1, whose fluctuation range decreases and drop about 25 percent to the trough between the fasteners. When the train loads are acted on the rail above the third or the sixth fastener, the bending moments reach its maximum value of $23.615 \mathrm{kN} \cdot \mathrm{m} / \mathrm{m}$ on the corresponding cross-section. And the bending moments along the width are relatively small on the end and middle of the board with the value of $16.110 \mathrm{kN} \cdot \mathrm{m} / \mathrm{m}$ and $17.764 \mathrm{kN} \cdot \mathrm{m} / \mathrm{m}$. As for the longitudinal negative bending moments, they vary smoothly along the width and tend to be stable along the length after increasing from the end of the board to the third fastener, which reach its maximum value of $7.680 \mathrm{kN} \cdot \mathrm{m} / \mathrm{m}$ on the cross-sections of the board below the fourth and fifth fastener when the rail above the end fastener is loaded.

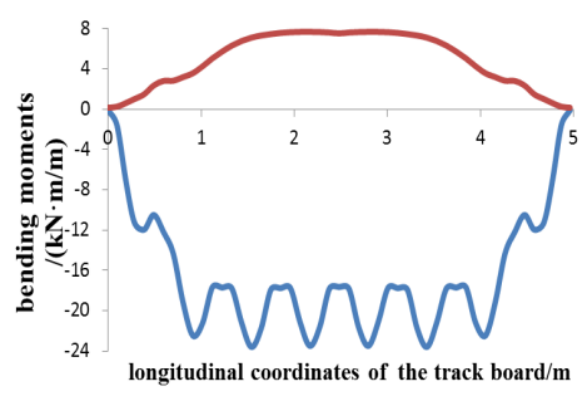

(a) distribution along the length of the board

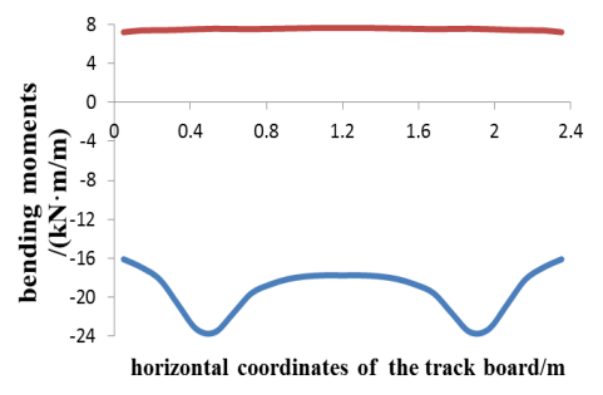

(b) distribution along the width of the board

Figure 4. The longitudinal envelope graph of bending moments in condition 2

Fig. 5 illustrates that the distribution of the transverse positive bending moments along the length of the board is similar to that in condition 1, whose fluctuation range decrease and drop about 20 percent to the trough between the fasteners. When the train loads are acted on the rail above the second or the seventh fastener, the bending moments reach its maximum value of $16.703 \mathrm{kN} \cdot \mathrm{m} / \mathrm{m}$ on the corresponding cross-section. As for the transverse negative bending moments, when the train 
loads are acted on the rail at the end of the board, the bending moments reach its maximum value of $8.121 \mathrm{kN} \cdot \mathrm{m} / \mathrm{m}$ at center of the end of the board and increase rapidly to the peak after $0.24 \mathrm{~B}$ from the end of the track board.

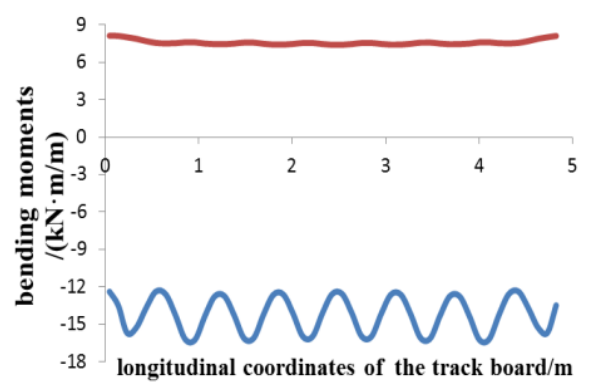

(a) distribution along the length of the board

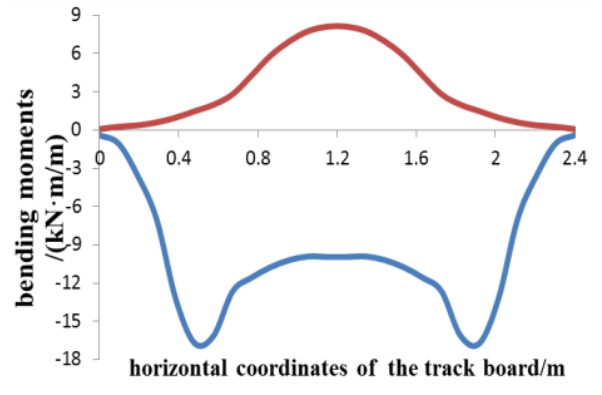

(b) distribution along the width of the board

Figure 5. The transverse envelope graph of bending moments in condition 2

\section{Conclusions}

(1)CRTS I ballastless track structure on subgrade should be designed under the most disadvantageous stressed state between design wheel load (Condition 1) and common wheel load with common temperature gradient (Condition 2).

(2)When the rail above the end fastener is loaded, the maximum value $(20.238 \mathrm{kN} \cdot \mathrm{m} / \mathrm{m})$ of the transverse positive bending moments of the track board occurs in condition 1.The maximum value of longitudinal negative bending moments $(7.680 \mathrm{kN} \cdot \mathrm{m} / \mathrm{m})$ and transverse negative bending moments $(8.121 \mathrm{kN} \cdot \mathrm{m} / \mathrm{m})$ occur in condition 2 . When the rail above the third or sixth fastener is loaded, the maximum value $(23.615 \mathrm{kN} \cdot \mathrm{m} / \mathrm{m})$ of the longitudinal positive bending moments occurs in condition 2 .

(3)The method has some reference value for the optimization design of the ballastless track structure and can be applied to obtain the envelope graph of bending moments, shear or axial force of structures in other fields, which can't be simplified as the beam or shell element.

\section{Acknowledgments}

The research described in this paper was financially supported by the Project of Innovation-driven Plan in Central South University (2015CXS014); the National Natural Science Foundation of China (Grant No. 51378513); the Joint Fund of the National Natural Science Foundation of China (Grant No. U1434204); the Science and Technology Foundation of Nanchang Railway Bureau (Grant No. 201524).

\section{References}

[1] Peng Limin. Numerical Method for Internal Force Transformation of Tunnel Structure [J]. Journal of Changsha Railway Institute, 1994, (1): 37 43.

[2] Zhou Zhengfan, Xiao Ming, Tang Fuping. Research on the Calculation Method of the Axial Force and Moment of Arbitrary Section Based on the Secondary Development of ANSYS [J]. China Rural Water and Hydropower, 2009, (1): 75 80.

[3] Xiong Gang, Yang Lipo. "Implementation of Internal Force Diagram of Solid Element Models Based on the Secondary Development of ANSYS [J]. Transportation and Computer, 2007, (4): 106 108. 
[4] Li Tongchun, Wen Zhaowang. "Finite Element Internal Force Method for Analysis of Arch Dam Stresses [J]. Journal of Hydroelectric Engineering, 2002, (4): 19 24.

[5] Yan Tianyou, Li Tongchun, Zhao Lanhao, Ren Hao. Comparison of Finite Element Method for Solving the Internal Force of Cross Section [J]. Hydropower Energy Science, 2008, (3): $141 \sim 143$.

[6] Wang Xinmin. ANSYS Numerical Analysis of Engineering Structures [M]. Beijing: China Communication Press, 2007.

[7] Liu Xueyi, Zhao Pingrui, Yang Rongshang, etc. The Design Theories and Methods of Passenger Dedicated Railway Line[M]. Chendu: Southwest Jiaotong University Press, 2010.

[8] Liang Fei. Mechanical Characteristic Research of CRTS I Slab Ballastless Track [D]. Changsha: Central South University, 2013.

[9] Liu Xiangming. Spatial Force Analysis of CRTS I Slab Ballastless Track on Subgrade [D]. Changsha: Central South University, 2012.

[10] Zhao Lei. Spatial Refinement Analysis Method of High Speed Railway Ballastless Track and Its Application Research [D]. Beijing: Beijing Jiaotong University, 2015. 